\title{
Superior vena cava stenosis at site of intersection of two pacing electrodes
}

\author{
MARINA PAULETTI, RAFFAELE PINGITORE, AND CARLO CONTINI \\ From CNR Clinical Physiology Laboratory; Institute of Pathological Anatomy and Histology, Medical \\ School; and Cardiology Division, University of Pisa, Ita!y
}

SUMMARY Superior vena cava obstruction is described in a patient with two endocardial pacing electrodes. At necropsy a severe stenosis of the venous lumen was found at the site of intersection of the two catheters. There was no evidence of thrombus formation. Venous wall stenosis is an unusual complication of transvenous pacing and is probably favoured by the presence of two electrodes.

Adhesion of endocardial pacing electrodes to the venous wall, endocardium, and tricuspid valve has been frequently described (Lagergren et al., 1966; Furman and Escher, 1968; Robboy et al., 1969; Camerini et al., 1973; Contini et al., 1973). Such lesions are usually devoid of clinical significance. However, under special circumstances, severe stenosis may develop, as in the case we describe in this paper.

The patient had two endocardial pacing electrodes (the second had been inserted because of frequent displacement of the first). Several years later he developed superior vena cava obstruction. At necropsy a severe venous stenosis was found at the site of intersection of the two electrodes.

We are unaware of any similar reported case.

\section{Case report}

A 55-year-old man was admitted with a one-year history of blackouts. The electrocardiogram showed atrial fibrillation with complete AV block and slow idioventricular rhythm. A permanent pacemaker system was inserted with an Elema EMT 588 endocardial electrode via the right external jugular vein. During the positioning manoeuvres the catheter repeatedly passed into the left atrium and lung fields, and later right heart catheterisation and cineangiocardiography showed that he had an atrial septal defect with left-to-right shunt and severe pulmonary arterial hypertension. During the following months the patient was readmitted to hospital several times with pacing failure. After numerous catheter replacements, a new Sorin C endocardial electrode was inserted via the left external jugular vein without removing the other electrode.
The subsequent period was uneventful until 7 years later, when the patient was readmitted with swelling of the head, neck, and upper extremities, which had developed over a few months. The chest $x$-ray film showed enlargement of the upper mediastinum, thought to be vascular. An isotopic venogram showed complete superior vena cava obstruction with a well-developed collateral circulation, especially via the intercostal veins. The obstruction was thought to be thrombotic in origin and intravenous heparin was started. This being unsuccessful, Urokinase was substituted for heparin. On the fourth day in hospital repetitive bursts of ventricular tachycardia occurred which were resistant to antiarrhythmic drugs. At the end of one of such episodes there was no response to the pacing stimuli and all attempts at resuscitation were unsuccessful.

Necropsy confirmed the clinical diagnosis of atrial septal defect, which was shown to be of the ostium secundum type (Fig. 1), with cardiomegaly $(790 \mathrm{~g})$, right ventricular hypertophy, and pronounced pulmonary vascular sclerosis. The Elema catheter (the smaller one) was attached to the septal cusp of the tricuspid valve, with its cut end in the right external jugular vein and the other end lying loose in the right ventricle. The lack of adhesion to the endocardium accounted for the frequent displacements. The Sorin catheter (which was connected to the pacemaker in the left pectoral area) passed via the left innominate vein and was firmly wedged in the trabecular system with extensive fibrous reaction. At the site where the two electrodes interesected (Fig. 2), at the junction of the innominate veins and the superior vena cava, there was severe stenosis of the lumen. The stenotic area, 


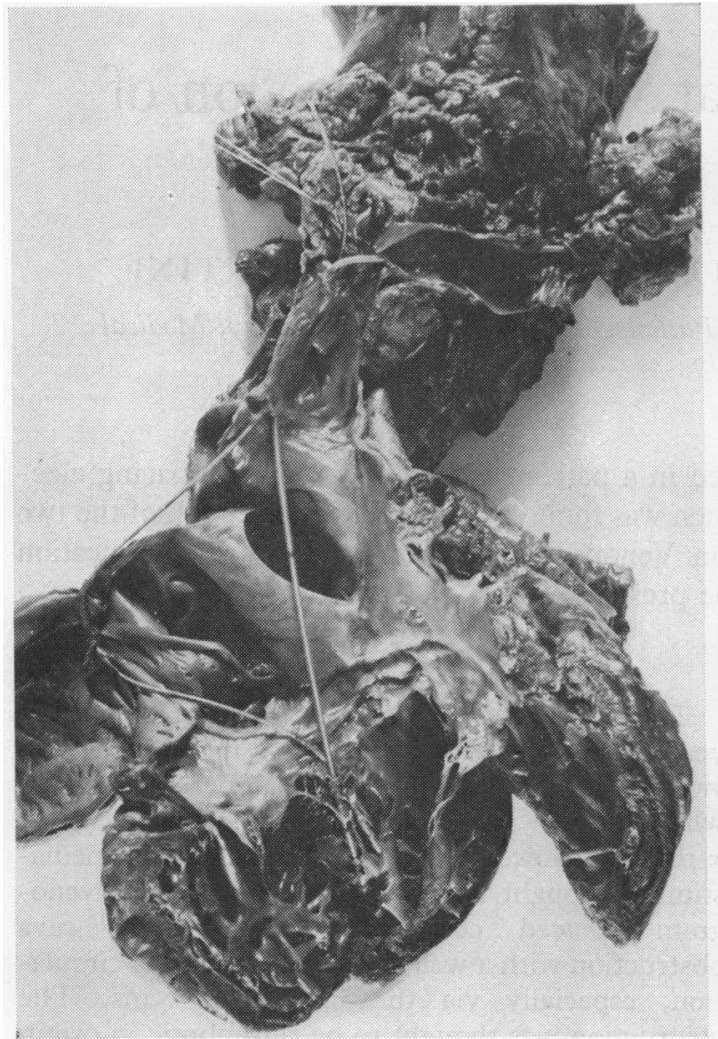

Fig. 1 Two pacing electrodes are present in the right cavities, the smaller one (EMT 588) passing via the right innominate vein, the larger one (Sorin) via the left innominate vein. The large atrial septal defect is visible.

which was also histologically examined, showed no evidence of organised thrombosis.

\section{Discussion}

Several cases of thrombosis around pacing electrodes have been reported (Lagergren et al., 1966; Youmans et al., 1967; Hager et al., 1968; Prozan et al., 1968; London et al., 1969; Reynolds et al., 1969; Robboy et al., 1969; Sidd et al., 1969; Griepp et al., 1970; Kaulbach and Krukonis, 1970; Wertheimer et al., 1973). To our knowledge only one case of superior vena cava syndrome in a pacemaker patient has been described (Wertheimer et al., 1973). It occurred in a patient with two bipolar catheters and was successfully managed with oral anticoagulants. The case is somewhat similar to our patient, who also had two pacing electrodes. However, while the case described by Wertheimer, even in the absence of a postmortem study, was probably

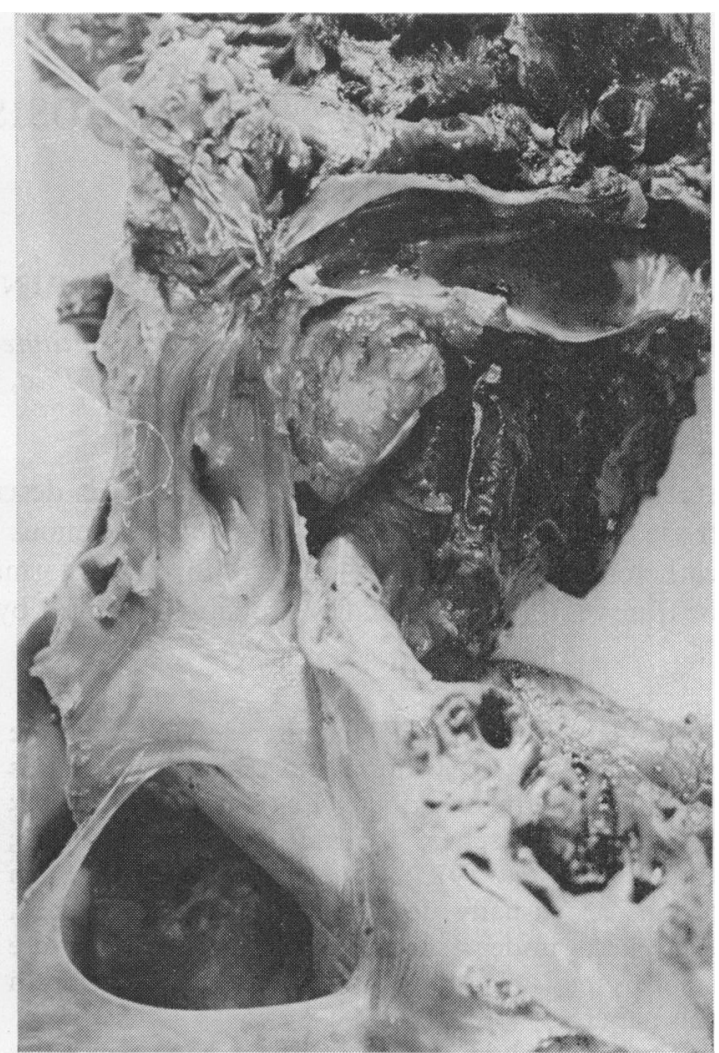

Fig. 2 The superior vena cava has been cut open and the two electrodes have been removed. A severe stenosis of the venous lumen is visible at the intersection of the two electrodes at the junction of the innominate veins.

caused by thrombosis, in our patient, the picture is typical of venous stenosis at the intersection of the two catheters, with no evidence of thrombosis. This is consistent with the failure of anticoagulant and fibrinolytic therapy.

This complication of endocardial pacing is, in our opinion, favoured by the presence of two electrodes, especially if passing via veins of opposite sides, owing to irritation of the venous wall at the intersection. Such a complication, though rare at present, is, in our opinion bound to be seen more frequently with the growing number of patients with two or more pacing electrodes. Now that pacemaker circuits and energy sources have become more reliable, the electrode represents the weak point of the pacing system, as risk of a break is still high. However, we believe one should not resort to a second (or third) catheter implantation without careful consideration. A lead break in the subcutaneous tract or at the entrance of the vein, for instance, may often be re- 
paired by suitable adaptors. Threshold problems may sometimes be managed by high energy pacemakers.

When implantation of a second electrode is absolutely necessary, we suggest the choice of a vein of the same side as that formerly used (e.g. the right jugular vein, when the first catheter has been inserted via the right cephalic), in order to avoid catheter crossing which may elicit fibrous tissue reaction and stenosis. Furthermore, one should always try to remove the old catheter, especially when, as in the case we have described, the tip is not anchored to the endocardium. When the old catheter is tightly fixed, as usually occurs, it may be worth while trying removal by weights.

\section{References}

Camerini, F., Giarelli, L., and Silvestri, F. (1973). L'anatomia patologica nella stimolazione elettrica del cuore. In $L a$ Stimolazione Elettrica del Cuore. Chapter 14, pp. 569-587. Ed. by P. Rossi. Piccin, Padova, Italy.

Contini, C., Papi, L., Pesola, A., Magini, G., L'Abbate, A., Magini, G., D'Angelo, T., Cinacchi, P., Maseri, A., and Donato, L. (1973). Tissue reaction to intracavitary electrodes: effect on duration and efficiency of unipolar pacing in patients with A-V block. Fournal of Cardiovascular Surgery, 14, 282-290.

Furman, S., and Escher, D. J. W. (1968). Retained endocardial pacemaker electrodes. Fournal of Thoracic and Cardiovascular Surgery, 55, 737-745.

Griepp, R. B., Daily, P. O., and Shumway, N. E. (1970). Subclavian-axillary vein thrombosis following implantation of a pacemaker catheter in the internal jugular vein. fournal of Thoracic and Cardiovascular Surgery, 60, 889892.

Hager, W., Hienz, H. A., and Düwell, H. J. (1968). Morphologische Veränderungen am Herzmuskel und an der
Gefässwand nach elektrischer Reizung des Herzens mit myokardialen und transvenös intrakardialen Elektroden. Thoraxchirurgie und Vaskuläre Chirurgie, 16, 143-160.

Kaulbach, M. G., and Krukonis, E. E. (1970). Pacemaker electrode induced thrombosis in the superior vena cava with pulmonary embolization. A complication of pervenous pacing. American fournal of Cardiology, 26, 205-207.

Lagergren, H., Dahlgren, S., and Nordenstam, H. (1966). Cardiovascular tissue response to intracardiac pacemaking. Acta Chirurgica Scandinavica, 132, 696-704.

London, A. R., Runge, P. J., Balsam, R. F., Bishop, M. B., and Bousvaros, G. (1969). Large right atrial thrombi surrounding permanent transvenous pacemakers. Circulation, 40, 661-664.

Prozan, G. B., Shipley, R. E., Madding, G. F., and Kennedy, P. A. (1968). Pulmonary thromboembolism in the presence of an endocardiac pacing catheter. Fournal of the American Medical Association, 206, 1564-1565.

Reynolds, J., Anslinger, D., Yore, R., and Paine, R. (1969). Transvenous cardiac pacemaker, mural thrombosis and pulmonary embolism. American Heart fournal, 78, 688-691.

Robboy, S. J., Harthorne, J. M., Leinbach, R. C., Sanders, C. A., and Austen, W. C. (1969). Autopsy findings with permanent pervenous pacemakers. Circulation, 39, 495-501.

Sidd, J. J., Stellar, L. I., Gryska, P. F., and O'Dea, A. E. (1969). Thrombus formation on a transvenous pacemaker electrode. New England fournal of Medicine, 280, 877-878.

Wertheimer, M., Hughes, R. K., and Castle, C. H. (1973). Superior vena cava syndrome. Complication of permanent transvenous endocardial cardiac pacing. Fournal of the American Medical Association, 224, 1172-1173.

Youmans, C. R., Jr., Derrick, J. R., and Wallace, J. M.(1967). Considerations of complications of permanent transvenous pacemakers. American fournal of Surgery, 114, 704-710.

Requests for reprints to Dr Carlo Contini, Divisione di Cardiologia, presso Istituto di Patologia Medica, Università di Pisa, Via Roma 57, Pisa, Italy. 